\title{
Douleur de la personne âgée
}

\section{Pain in the elderly}

Face à une population de plus en plus vieillissante, la prise en charge de la douleur de la personne âgée est plus que jamais d'actualité. Ce thème a fait l'objet du dixième numéro de la lettre, La douleur, des recommandations à la pratique, éditée par l'institut UPSA de la douleur et sera le sujet traité dans le prochain ouvrage qui sera publié par l'institut.

La vieillesse est un processus naturel, mais quand elle s'associe à des douleurs chroniques, articulaires ou bien aiguës ayant des répercussions sur les capacités de la personne âgée, sur sa qualité de vie, une prise en charge médicale adaptée est nécessaire.

Le rôle des acteurs du monde médical est de veiller à ce que cet état soit pris en charge de façon optimale en prenant en compte les trois dimensions que recouvre la douleur: dimensions organique, psychologique et sociale.

Parce qu'être âgé et souffrir est souvent considéré à tort comme normal, la problématique de la douleur chez la personne âgée se doit d'être éclairée.

Qu'est-ce que la douleur chronique du sujet âgé ? Comment cette douleur est-elle évaluée et prise en charge par le médecin?

Cette publication est disponible sur le site Internet de l'institut : www.institut-upsa-douleur.org.

\section{Conflit d'intérêt : aucun.}

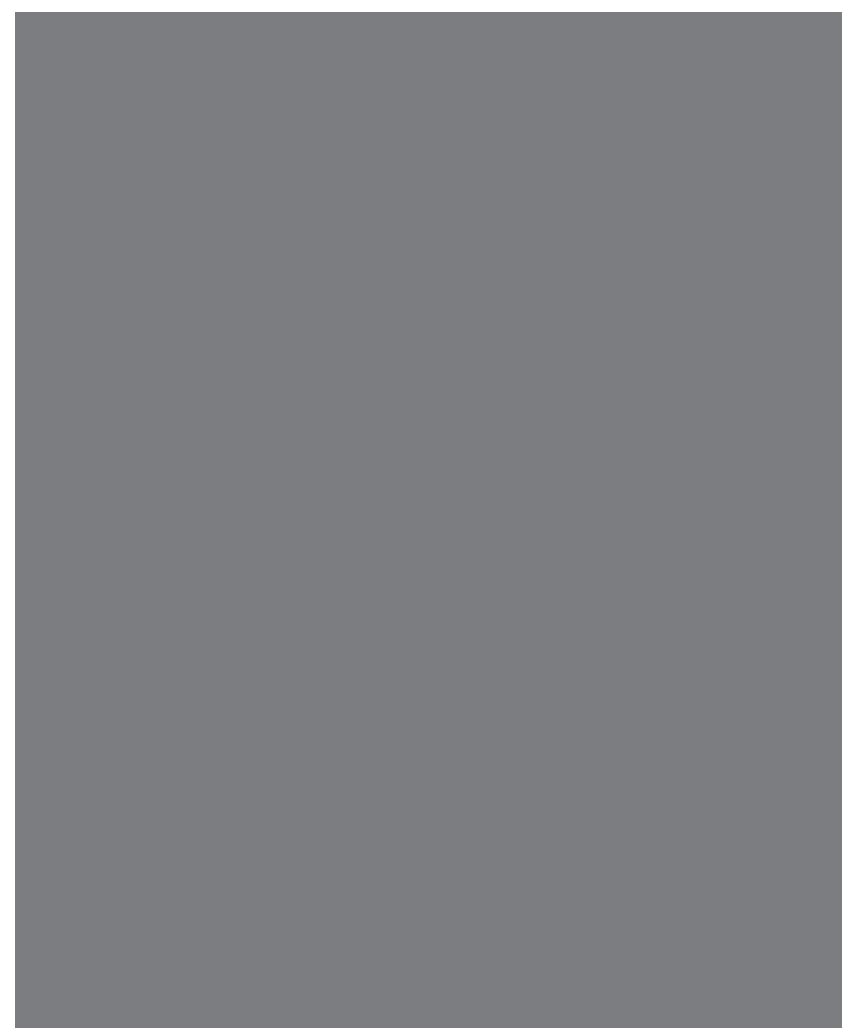

